NBER WORKING PAPER SERIES

\title{
INEQUALITY, PREDATION AND WELFARE
}

Herschel I. Grossman

Minseong Kim

NBER Working Paper 5704

\section{NATIONAL BUREAU OF ECONOMIC RESEARCH 1050 Massachusetts Avenue \\ Cambridge, MA 02138}

August 1996

We acknowledge helpful comments from participants in the Income Distribution Workshop at the National Bureau of Economic Research 1996 Summer Institute. This paper is part of NBER's research program in Economic Fluctuations and Growth. Any opinions expressed are those of the authors and not those of the National Bureau of Economic Research.

(C) 1996 by Herschel I. Grossman and Minseong Kim. All rights reserved. Short sections of text, not to exceed two paragraphs, may be quoted without explicit permission provided that full credit, including $(\odot$ notice, is given to the source. 


\title{
INEQUALITY, PREDATION AND WELFARE
}

\begin{abstract}
This paper studies the relation between inequality and welfare in a general-equilibrium model in which people can choose to be either producers or predators. We assume that some people (the privileged) are well endowed with human capital and other people (the unprivileged) are poorly endowed with human capital.

We analyze how the choice of the privileged between deterring and tolerating predation by the unprivileged depends on the interpersonal distribution of human capital. We find that, if the number of people who are unprivileged is large, but a privileged person does not have too much human capital relative to an unprivileged person, then the privileged allocate enough time and effort to guarding against predation to deter the unprivileged from being predators. Otherwise, the privileged tolerate predation by the unprivileged. Interestingly, a distribution of human capital that is more egalitarian in that the number of people who are unprivileged is smaller can result in the privileged choosing to tolerate rather than to deter predation by the unprivileged.

Next, we partition the feasible distributions of human capital into a set of Pareto efficient distributions and a set of Pareto inefficient distributions. Interestingly, we find that if the average endowment of human capital is large, then the fully egalitarian distribution is not Pareto efficient. Instead, Pareto efficiency implies an unegalitarian distribution of human capital in which each unprivileged person has only the endowment of human capital with which he was born. In addition, this unegalitarian distribution satisfies the Rawlsian criterion of maximizing the consumption of the unprivileged. With this unegalitarian distribution the privileged choose to tolerate predation by the unprivileged, and predation results in maximum consumption for everyone.
\end{abstract}

Herschel I. Grossman

Department of Economics

Box B

Brown University

Providence, RI 02912

and NBER

herschel@brownvm.brown.edu
Minseong Kim

Department of Economics University of Pittsburgh

Pittsburgh, PA 15260 
Mr. Benson looks to the future and sees a widening social abyss. "We could get to a situation similar to Manila, where the upper and middle classes surround themselves with walls and security guards to protect themselves from an abandoned underclass." ... When asked about Mr Benson's fear of an urban America that looks like Manila, Mr Newsome shrugs: "It's already like that," he says. (The Wall Street Journal, September 26, 1995, page A8.)

This paper studies the relation between inequality and welfare in a general-equilibrium model in which people can choose to be either producers or predators. Predators are people who produce nothing, but live by appropriating the product of the producers. ${ }^{1}$ We assume that a person chooses to be a predator rather than a producer if and only if predation yields higher consumption for that person than would production.

We consider a society in which some people (the privileged) are well endowed with human capital, but in which other people (the unprivileged) are poorly endowed with human capital. In this society, the interpersonal distribution of human capital has two dimensions: the number of people who are unprivileged and the endowment of the human capital of a privileged person relative to the endowment of an unprivileged person. Given the aggregate endowment of human capital, it seems natural to define a distribution to be more egalitarian either if the number of people who are unprivileged is smaller or if the ratio of the human capital of a privileged person to the human capital of an unprivileged person is smaller.

Given that the consumption that a person can obtain from being a producer is an increasing function of that person's human capital, the unprivileged find predation more attractive than the privileged. ${ }^{2}$ We assume that the privileged have two alternative ways

\footnotetext{
${ }^{1}$ This paper is about predation. It is not about crime. Predation and crime are not the same thing. Although many predatory activities, like burglary and robbery, are criminal, many criminal activities, like illegal gambling and drug dealing, are productive and not predatory. Also, some predatory activities, like the collection of taxes to support a parasitic ruling class, are not criminal.

${ }^{2}$ In this model the only distinguishing characteristic of people who choose to be predators is that they have
} 
to respond to the threat of predation by the unprivileged. One possibility is to allocate enough time and effort to guarding against predation to deter the unprivileged from being predators. The other possibility is to tolerate predation by the unprivileged. ${ }^{3}$

We analyse how the choice of the privileged between deterring and tolerating pre-

relatively little human capital and, hence, relatively poor productive opportunities. A popular alteruative view is that predators lack the moral attributes of honest and liard working people. In fact, both of these answers could be correct - people who choose to be predators might lack both the moral atributes and the productive opportunities that other people have. Wong (1995) contains a brief review of some of the relevant literature.

In another paper - Grossman and $\operatorname{Kim}(1996 \mathrm{~b})$ - we analyse the intensity of predation in a model in which only some people, whom we define to be amoral, are potential predators. The other people, whom we define to be moral, always choose to be producers, no matter how lucrative predation is relative to production. In the present paper we implicitly assume that everybody is amoral. Hence, every person is a potential predator.

${ }^{3}$ Economic models of predation analyse choices about resource allocation. In this respect economic models differ radically from biological models of predation. Most importantly, in economic models a potential predator can choose not to be a predator if production is more lucrative than predation. In contrast. a biological predator does not have the alternative of being a producer. In addition, in the present model a potential prey can choose to allocate resources to deterrence, another option that does not exist in a biological model.

In pioneering general-equilibrium models that allow for predation, Usher (1987) and Moselle and Polak (1995) analyse equilibria in which people decide simultaneously whether to be producers or predators. [Also, in Usher's model producers decide how much time and effort to put into guarding against predation.] In these models each person takes as given the decisions of other people to be producers or predators. Thus, neither of these papers considers the possibility of a strategy of deterring predation.

In two previous papers - Grossman and Kim $(1995,1996 a)$ - we developed general-equilibrium models of appropriative interaction between a pair of unitary agents in which a prey can act to deter a potential predator. The first of these papers, however, abstracted from the possibility that an agent would choose to specialize in predation. The second of these papers was more closely related to the present paper in that. it allowed a potential predator to choose to specialize in either predation or production. But, the role of prey was preassigned. By choosing to specialize in production, the potential predator did not become a prey. In contrast, in the present paper, as in Grossman and Kim (1996b), every potential predator is also a potential prey. 
dation depends on the interpersonal distribution of human capital. We find that if the number of people who are unprivileged is large, but a privileged person does not have too much human capital relative to an unprivileged person, then the privileged allocate enough time and effort to guarding against predation to deter the unprivileged from being predators. Otherwise, the privileged tolerate predation by the unprivileged. Interestingly. a distribution of human capital that is more egalitarian in that the number of people who are unprivileged is smaller can result in the privileged choosing to tolerate rather than to deter predation by the unprivileged.

Next, we partition the feasible distributions of human capital into a set of Pareto efficient distributions and a set of Pareto inefficient distributions. The key to understanding Pareto efficiency in this model that allows predation is to observe that the possibility of predation can affect aggregate net consumption in two distinct ways. First, any tine and effort devoted to guarding against predation reduces the net consumption of producers. Second, if the privileged tolerate predation by the unprivileged, then the human capital of the unprivileged is wasted by not being used productively.

We find that the partition between Pareto efficient distributions and Pareto inefficient distributions depends on the economy's average endowment of human capital. Specifically, if the average endowment of human capital is small, then both the fully egalitarian distribution as well as some of the distributions of human capital such that the privileged choose to deter predation by the unprivileged are Pareto efficient. But, if the average endowment of human capital is large, then the fully egalitarian distribution is not Pareto efficient. Instead, Pareto efficiency implies a distribution of human capital with a positive number of unprivileged people and with each unprivileged person having only the endowment of human capital with which he was born. With this distribution the privileged choose to tolerate predation by the unprivileged.

Then, we apply the Rawlsian criterion, from Rawls (1971), and we determine which of the Pareto efficient distributions maximizes the net consumption of the each unprivileged 
person. Another interesting result is that with the possibility of predation, if the average endowment of human capital is large enough, then the Rawlsian criterion would select the distribution of human capital with a positive number of unprivileged people and with each unprivileged person having only the endowment of human capital with which he was born. With this unegalitarian distribution of human capital, predation results in maxinum consumption for everyone.

\section{Analytical Framework}

Assume that each unprivileged person has an endowment of $k$ units of human capital, and that each privileged person has an endowment of $K$ units of human capital, where $K \geq k$. Also, assume that each person can produce an amount of consumables that is an increasing concave function of his human capital. We choose units for measuring consumables such that an unprivileged producer can produce $k^{\alpha}$ units of consumables and a privileged producer can produce $K^{\alpha}$ units of consumables, where $0<\alpha<1$. To focus on the effects of the possibility of predation, we assume that individual productive activities are independent, and we abstract from trade in either productive inputs or consumables. ${ }^{4}$ Finally, assume that $u$ is the number of people who are unprivileged, and that $1-u$ is the number of people who are privileged, where we choose units such that the population is one and where $0 \leq u<1$. Aside from their endowments of human capital, people are otherwise identical.

Let $n$ be the number of people who are unprivileged and who choose to be producers, where $n \leq u$, let $N$ be the number of people who are privileged and who choose to be producers, where $N \leq 1-u$, and let $r$ be the number of people, whether privileged or unprivileged, who choose to be predators. Thus, we have $n+N+r=1$.

Each producer retains the nonnegative fraction $p$ of his production, while losing the

\footnotetext{
${ }^{4}$ Skaperdas and Syropoulos (1996) develop a model of predation with trade. But, in sharp contrast with the present paper, they analyse the interaction between two unitary agents who make simultaneous resource allocation decisions.
} 
nonnegative fraction $1-p$ to predation. Assume that $p$ depends negatively on number of predators and positively on the total amount of time and effort that producers devote to guarding against predation, denoted by $\Sigma G$. Specifically,

$$
p=\frac{1}{1+\theta r / \Sigma G} .
$$

The parameter $\theta$ in equation (1) determines the effectiveness of predators in appropriating the product of producers relative to the time and effort of producers in guarding against predation.

Assume further that the relative contribution of time and effort by each producer to guarding against predation is proportionate to his production. Specifically, each unprivileged producer devotes a nonnegative amount of time and effort $k^{\alpha} G$ to guarding against predation, and each privileged producer devotes a nonnegative amount of time and effort $K^{\alpha} G$ to guarding against predation, Thus,

$$
\Sigma G=\left(n k^{\alpha}+N K^{\alpha}\right) G
$$

Let $z$ denote the net consumption of each unprivileged producer and let $Z$ denote the net consumption of each privileged producer after allowing for losses to predation and for the opportunity cost of devoting time and effort to guarding against predation. It is convenient to assume that

$$
z=\frac{p k^{\alpha}}{1+\gamma k^{\alpha} G} \text { and } Z=\frac{p K^{\alpha}}{1+\gamma K^{\alpha} G},
$$

where $1>\gamma \theta>0$. In equation (3), we can interpret $z$ and $Z$ to be the amounts of consumption that with no time and effort devoted to guarding against predation - that is, with $G=0$ - would yield the same utility as the actual combinations, $p k^{\alpha}$ and $k^{\alpha} G$ and $P K^{\alpha}$ and $K^{\alpha} G$. The parameter $\gamma$ in equation (3) converts the opportunity cost of devoting time and effort to guarding against predation into units of consumption.

Assume that the consumption of each predator, denoted by $v$, is

$$
v=\frac{(1-p)\left(n k^{\alpha}+N K^{\alpha}\right)}{r} .
$$


Equation (4) says that each predator obtains an equal share of the total anount of product appropriated from the producers. ${ }^{5}$

We want our model to capture the fact that guarding against predation can deter predation. The concept of deterrence implies a game between a unitary leader and one or more followers. Accordingly, we assume that decisions are made in the following order.

First, the privileged decide collectively how much time and effort each producer will devote to guarding against predation. In choosing $G$ the privileged take into account the effect of $k^{\alpha} G$ and $K^{\alpha} G$ on the choice of both the privileged and the unprivileged to be predators. Because in equilibrium the privileged choose to be producers, the objective of the privileged is to maximize $Z$, the net consumption of each privileged producer.

Second, taking $k^{\alpha} G$ and $K^{\alpha} G$ as given, each person decides whether to be a producer or a predator. For a privileged person, this choice depends on whether or not, for the given values of $k^{\alpha} G$ and $K^{\alpha} G, Z$ is as large as $v$. For a unprivileged person, this choice depends on whether or not, for the given values of $k^{\alpha} G$ and $K^{\alpha} G, z$ is as large as $v$.

\section{Deterrence or Toleration of Predation?}

To analyze this model, we begin by considering the decisions of the privileged and the unprivileged to be producers or predators. By substituting equations (1) and (2) into equations (3) and (4), we find that $Z \geq v$ if and only if $G \geq G^{*}(K)$, where

$$
G^{*}(K)=\frac{\theta}{K^{\alpha}(1-\gamma \theta)} .
$$

In addition, we find that $z \geq v$ if and only if $G \geq G^{*}(k)$, where

$$
G^{*}(k)=\frac{\theta}{k^{\alpha}(1-\gamma \theta)}
$$

\footnotetext{
${ }^{5}$ For simplicity, the model abstracts from possible destruction of a part of the product as the result of predation. The models in Grossman and Kim (1995, 1996a) suggest how destruction could be incorporated into the analysis. With regard to the results derived below, destruction would make it less likely that Pareto efficiency would imply toleration of predation.
} 
These results say that, if and only if $G \geq G^{*}\left(K^{\circ}\right)$. then all of the privileged people choose to be producers. In other words, $K^{\circ} G^{\times}(K)$ is the minimum amonnt of time and effort that each privileged producer must devote to guarding against predation to deter privileged people from being predators and to support a nontrivial equilibriun with positive production. In addition, if and only if $G \geq G^{*}(k)$. where $G^{*}(k)$ is larger than $G^{*}(K)$. then all of the unprivileged people choose to be producers. In other words, $k^{* x} G^{*}(k)$ and $K^{\alpha} G^{*}(k)$ are the minimum amounts of time and effort that each unprivileged producer and each privileged producer would have to devote to guarding against predation in order to deter the unprivileged from being predators. ${ }^{6}$

In sum, we have

$$
r=\left\{\begin{array}{l}
0 \text { for } G \geq G^{*}(k) \\
u \text { for } G^{*}(k)>G \geq G^{*}(K)
\end{array}\right.
$$

Equation (7) says that, if $G$ is at least as large as $G^{*}(k)$, then everybody chooses to be a producer. Alternatively, if $G^{*}(k)>G \geq G^{*}(K)$. then the privileged choose to be producers and the unprivileged choose to be predators.

We consider next the collective decision of the privileged regarding $G$. As indicated above, the objective of the privileged is to maximize $Z$. To simplify the analysis we assume that the privileged choose either $G$ equal to $G^{*}(K)$ or $G$ equal to $G^{*}(k){ }^{7}$

\footnotetext{
${ }^{6}$ In this model $G^{*}(k)$ does not depend on $u$, the number of unprivileged people, because the consumption of a predator relative to the net consumption of an unprivileged producer does not depend on $r$, the number of predators. With a larger number of predators the fraction of production that predators appropriate would be larger relative to the fraction of production that producers retain, but each predator's share of the total amount appropriated from producers would be smaller.

${ }^{7}$ This assumption abstracts from the possibility that the maximum value of $Z$ occurs with $G$ equal to $G^{\prime}$, where $G^{\prime}$ is the solution to the first-order condition for an interior maximum, $d Z / d G=0$, given $\boldsymbol{r}=u$. In general, $Z$ has a local maximum at $G=G^{*}(k)$, and $Z$ can have additional local maxima either at $G=G^{*}(K)$ or at $G=G^{\prime}=\frac{1}{K^{\alpha}} \sqrt{\frac{u}{1-u} \frac{\theta}{\gamma}}$. If $G^{\prime} \leq G^{*}(K)$, then $G^{*}(K)$ and $G^{*}(k)$ are
} 
To determine the choice of $G$ we compare the value of $Z$ associated with $G^{*}(K)$. denoted as $Z\left[G^{*}(K)\right]$, and the value of $Z$ associated with $G^{*}(k)$, denoted as $Z\left[G^{*}(k)\right]$. Substituting for $G^{*}(K)$ and $G^{*}(k)$ from equations (5) and (6), together with equations $(1),(2)$, and (7), into equation (3), we obtain

$$
Z\left[G^{*}(K)\right]=\frac{K^{\alpha}}{1+\frac{\gamma \theta}{1-\gamma \theta}+\frac{u}{1-u}}
$$

and

$$
Z\left[G^{*}(k)\right]=\frac{K^{\alpha}}{1+\left(\frac{K}{k}\right)^{\alpha} \frac{\gamma \theta}{1-\gamma^{\theta}}} .
$$

Important properties of equations (8) and (9) are that both $Z\left[G^{*}(K)\right]$ and $Z\left[G^{*}(k)\right]$ are increasing functions of $K$. Also, $Z\left[G^{*}(K)\right]$ is a decreasing function of $u$, but, given $K$, $Z\left[G^{*}(K)\right]$ does not depend on $K / k$. In contrast, given $K, Z\left[G^{*}(k)\right]$ is a decreasing function of $K / k$, but $Z\left[G^{*}(k)\right]$ does not depend on $u$.

Comparing the values of $Z\left[G^{*}(K)\right]$ and $Z\left[G^{*}(k)\right]$, we see that equations (8) and (9) imply that the choice of $G$ by the privileged that maximizes $Z$ is

$$
G= \begin{cases}G^{*}(k) \text { for } \frac{u}{1-u} \geq \frac{\gamma \theta}{1-\gamma \theta}\left[\left(\frac{K}{k}\right)^{\alpha}-1\right] \\ G^{*}(K) \text { for } \frac{u}{1-u}<\frac{\gamma \theta}{1-\gamma \theta}\left[\left(\frac{K}{k}\right)^{\alpha}-1\right]\end{cases}
$$

Thus, the number of people who choose to be predators, $r$, is

$$
r=\left\{\begin{array}{l}
0 \text { for } \frac{u}{1-u} \geq \frac{\gamma \theta}{1-\gamma \theta}\left[\left(\frac{K}{k}\right)^{\alpha}-1\right] \\
u \text { for } \frac{u}{1-u}<\frac{\gamma \theta}{1-\gamma \theta}\left[\left(\frac{K}{k}\right)^{\alpha}-1\right]
\end{array}\right.
$$

local maxima and $G^{\prime}$ is not a local maximum. If $G^{*}(K)<G^{\prime}<G^{*}(k)$, then $G^{\prime}$ and $G^{*}(k)$ are local maxima and $G^{*}(K)$ is not a local maximum. Otherwise, $G^{*}(k)$ is the unique local maximum. A sufficient condition to preclude the possibility that $G^{\prime}$ is the global maximum is that the ratio $K / k$ is not too large - specifically, $\left[(K / k)^{\alpha}-1\right](1-\gamma \theta)<1$. This condition says that $K / k$ is smaller than a number that is larger than two. 
Equations (10) and (11) imply that, if the number of people who are unprivileged. $u$, is large, but the ratio of the human capital of a privileged person to the human capital of an unprivileged person, $K / k$, is not large, then the privileged producers devote sufficient time and effort to guarding against predation to deter the unprivileged from predation. Otherwise, the privileged producers choose to tolerate predation by the unprivileged. Equation (10) also implies that the larger is $u$ the larger is the largest value of $K / k$ for which the privileged producers choose to deter predation by the unprivileged.

A small value of $u$ induces the privileged producers to tolerate predation because, if $u$ is small, then, even with $r$ equal to $u, p$ is not too much less than one. In other words, if $u$ is small, then the loss to producers from tolerating predation is small. ${ }^{8}$ A large value of $K / k$ induces the privileged producers to tolerate predation because, if $K / k$ is large, then, from equations (5) and (6), $G^{*}(k)$ is large relative to $G^{*}(K)$. In other words, if $K / k$ is large, then deterring the unprivileged from predation would require each producer to allocate a relatively large amount of time and effort to guarding against predation.

As mentioned above, it seems natural to define a distribution of human capital to be more egalitarian if, given the aggregate endowment of human capital, either $u$ is smaller (closer to zero) or $K / k$ is smaller (closer to one). The limiting distribution that has $u$ equal to zero is identical to the limiting distribution that has $K / k$ equal to one. This limiting distribution is fully egalitarian in that the distinction between privileged and unprivileged people has disappeared. (With either $u$ equal to zero or, equivalently, $K / k$ equal to one, setting $G$ equal to $G^{*}(K)$ would deter everyone from predation.)

Interestingly, a smaller value of $u$ and a smaller value of $K / k$ affect the choice between deterrence and toleration of predation in opposite ways. A distribution of human capital that is more egalitarian in that $K / k$ is smaller, if anything, would result in the

\footnotetext{
${ }^{8}$ Given $K / k$ and given the aggregate endowment of human capital, denoted by $\Omega$, a smaller value of $u$ implies smaller values of both $K$ and $k$. From equation (12), which is intraduced below, we see that $\left.\frac{d k}{d u}\right|_{\Omega, K / k}=(K-k) \frac{k}{\Omega}$.
} 
privileged producers choosing to deter rather than to tolerate predation. But a distribution of human capital that is more egalitarian in that $u$ is smaller, if anything, would result in the privileged producers choosing to tolerate rather than to deter predation.

Equations (10) and (11) also imply that the relation between $u$ and $r$, the number of people who choose to be predators, is neither continuous nor monotonic. Suppose tliat the distribution of human capital is such that the privileged producers choose to tolerate predation by the unprivileged. Hence, $r$ equals $u$. In this case, with a decrease in $u$ the privileged producers would continue to tolerate predation by the unprivileged, as long as $u$ remains positive. (As we have noted, with $u$ equal to zero the distinction between privileged and unprivileged people has disappeared, and everyone is deterred from predation.) Thus, with $r$ equal to $u$ a decrease in $u$ would imply a decrease in $r$.

Alternatively, suppose that the distribution of human capital is such that the privileged producers choose to deter predation. Hence, $r$ equals zero. In this case, a sufficient decrease in $u$ would cause the privileged producers to choose instead to tolerate predation by the unprivileged. Thus, with a large value of $u$, but $r$ equal to zero, a decrease in $u$ could cause $r$ to become positive.

\section{Pareto Efficient Distributions of Human Capital}

This section analyses the welfare properties of the interpersonal distribution of human capital. We partition the feasible distributions of human capital into a set of Pareto efficient distributions and a set of Pareto inefficient distributions. A Pareto efficient distribution is a. distribution such that there is no feasible redistribution of human capital that would result in a. Pareto improvement. A Pareto improvement is an increase in the net consumption of at least one person without a decrease in the net consumption of any other person.

Because this model assumes that individual productive activities are independent, and the model also abstracts from trade, if we were to ignore the possibility of predation, then all interpersonal distributions of human capital would be Pareto efficient. Without 
the possibility of predation, any redistribution of human capital would reduce somebody's consumption. Allowing for the possibility of predation, however, introduces the possibility that a redistribution of human capital could result in a Pareto improvement.

As mentioned above, the key to understanding Pareto efficiency in this model that allows predation is to observe that the possibility of predation can affect aggregate net consumption in two distinct ways. First, any time and effort devoted to guarding against predation reduces the net consumption of producers. Second, if the producers tolerate predation by the unprivileged, then the human capital of the unprivileged is wasted by not being used productively.

Let $\Omega$ denote the aggregate endowment of human capital. Thus,

$$
\Omega=(1-u) K+u k
$$

In analysing the welfare properties of the interpersonal distribution of human capital, we hold $\Omega$ fixed.

Assume that by virtue of birth every person has a nonnegative endowment of $k_{u}$ units of human capital. Presumably, $k_{0}$ varies little across economies. Assume further that, although education or training can increase a person's endowment of human capital, a person's endowment of human capital cannot be decreased. Thus, for a given value of $\Omega$, a feasible interpersonal distribution of human capital is any combination of $k, K$, and $u$ that satisfies equation (12) subject to $K \geq k \geq k_{0} \geq 0$.

\subsection{Pareto Efficiency with Deterrence}

Consider the set of distributions of human capital that are feasible and Pareto efficient conditional on either the distribution being such that the privileged choose to deter predation by the unprivileged or the distribution being fully egalitarian. With either deterrence or the fully egalitarian distribution, the net consumption of a privileged person is $Z\left[G^{*}(k)\right]$, as given by equation (9). Also, by substituting equation (6) into equation (3), 
we see that $z$, the net consumption of an unprivileged person. is

$$
z=(1-\gamma \theta) k^{\alpha}
$$

Equation (13) says that $z$ is an increasing function of $k$. Accordingly, any redistribution of human capital that decreased $k$, the louman capital of an unprivileged person, would decrease the net consumption of unprivileged people, and any redistribution of human capital that increased $k$ would increase the net consumption of the unprivileged people.

In addition, comparing equations (9) and (13) we see that, if $K$ is larger than $k$, then $Z\left[G^{*}(k)\right]$ is larger than $z$. In other words, with deterrence, the net consumption of a privileged person is larger than the net consumption of an unprivileged person. An increase in $u$ would imply a change in the status of some people from being privileged to being unprivileged. As long as $K$ is larger than $k$, any redistribution of human capital that increased $u$ would decrease the net consumption of these people.

Equation (12) implies that

$$
\left.\frac{d K}{d u}\right|_{k}=\frac{\Omega-k}{(1-u)^{2}}
$$

Using equations (9) and (14) we find that, given $k, Z\left[G^{*}(k)\right]$ is an increasing function of $u$. Accordingly, with deterrence, given $k$, any redistribution of human capital that decreased $u$ would decrease the net consumption of privileged people.

These observations imply that, with deterrence, any redistribution of human capital that either decreased $k$ or increased $u$ or, given $k$, decreased $u$ would not result in a Pareto improvement. Also, any redistribution of human capital that increased $k$ would increase the net consumption of the unprivileged people. Thus, to determine the set of Pareto efficient distributions of human capital, we have only to partition the feasible distributions according to whether or not increasing $k$, the human capital of an unprivileged person, would decrease $Z\left[G^{*}(k)\right]$, the net consumption of privileged people. 
Equation (12) also implies that

$$
\left.\frac{d K}{d k}\right|_{u}=-\frac{u}{1-u}
$$

Using equations (9) and (15) we obtain

$$
\left.\frac{d Z\left[G^{*}(k)\right]}{d k}\right|_{u} \geq 0 \text { if and only if } K / k \geq \max \left[(K / k)^{\circ}, 1\right]
$$

where $\left(\frac{K}{k}\right)^{\circ}=\left(\frac{u}{1-u} / \frac{\gamma \theta}{1-\gamma \theta}\right)^{\frac{1}{1+\alpha}}$.

Condition (16) implies that, given $u$, if and only if $K / k \geq \max \left[(K / k)^{0}, 1\right]$, then increasing $k$ and decreasing $K$ would increase the net consumption of privileged people and, hence, would result in a Pareto improvement. Thus, with either deterrence or the fully egalitarian distribution, all distributions of human capital such that $K / k \geq \max \left[(K / k)^{\circ}, 1\right]$ are Pareto inefficient. This result reflects the fact that, if $K / k$ is sufficiently large, then increasing $k$ and decreasing $K$ would result in a large decrease in $K^{\alpha} G^{*}(k)$, the amount of time and effort that the privileged have to devote to guarding against predation in order to deter the unprivileged from being predators, relative to the decrease in the production of the privileged.

In sum, we have found that, with either deterrence or the fully egalitarian distribution, if and only if the distribution of human capital is such that either $k \geq k_{0}$ and $1<K / k<$ $(K / k)^{\circ}$ or $K / k=1$, then no feasible redistribution of human capital would result in a Pareto improvement. Thus, with either deterrence or the fully egalitarian distribution, all distributions of human capital such that either $k \geq k_{0}$ and $1<K / k<(K / k)^{\circ}$ or $K / k=1$ are feasible and Pareto efficient.

What amounts of net consumption by the privileged and the unprivileged are associated with these conditionally Pareto efficient distributions? Given the specification of $(K / k)^{\circ}$, equations (9) and (13), together with equation (12), imply that

$$
Z\left[G^{*}(k)\right]=z=(1-\gamma \theta) \Omega^{\alpha} \quad \text { if } K / k=1
$$


and that

$$
\sup \left\{Z\left[G^{*}(k)\right]\right\}>Z\left[G^{*}(k)\right]>(1-\gamma \theta) \Omega^{\alpha}>z \quad \text { if } 1<K / k<(K / k)^{\circ},
$$

where $\sup \left\{Z\left[G^{*}(k)\right]\right\}=\frac{\left[1+\left(\frac{K}{k}\right)^{1+\alpha} \frac{\gamma \theta}{1-\gamma^{\theta}}\right]^{\alpha}}{\left[1+\left(\frac{K}{k}\right)^{\alpha} \frac{\gamma \theta}{1-\gamma \theta}\right]^{1+\alpha}} \Omega^{\alpha}$ and $K / k=(K / k)^{\circ}$.

The variable $\sup \left\{Z\left[G^{*}(k)\right]\right\}$ denotes the supremum of $Z\left[G^{*}(k)\right]$.

\subsection{Pareto Efficiency with Toleration}

Now, consider the set of distributions of human capital that are feasible and Pareto efficient conditional on either the distribution being such that the privileged choose to tolerate predation by the unprivileged or the distribution being fully egalitarian. With either toleration or the fully egalitarian distribution, the net consumption of a privileged person is $Z\left[G^{*}(K)\right]$, as given by equation (8). Also, because $K G^{*}(K)$ is the minimum amount of time and effort that each privileged producer must devote to guarding against predation to deter privileged people from being predators, with $G=G^{*}(K), Z\left[G^{*}(K)\right]$ is equal to $v$, the consumption of a predator. Thus, with either the privileged tolerating predation by the unprivileged or a fully egalitarian distribution, everyone, whether privileged or unprivileged, has the same net consumption. Hence, to determine the set of conditionally Рагеto efficient distributions of human capital, we only have to find the set of distributions for which the net consumption of a privileged person, $Z\left[G^{*}(K)\right]$, is maximized.

Using equations (8) and (15) we obtain

$$
\left.\frac{d Z\left[G^{*}(K)\right]}{d k}\right|_{u} \leq 0 \quad \text { as } \quad u \geq 0
$$

Condition (19) implies that, if $u$ is positive, then the value of $k$ that maximizes $Z\left[G^{*}(K)\right]$ is the minimum value, $k_{0}$, which is every person's minimum endowment of human capital. With toleration, setting $k$ equal to $k_{0}$ minimizes the amount of human capital that the unprivileged waste by being predators rather than producers.

Using equations (8) and (14) we find that, given $k$, the value of $u$ that maximizes 
$Z\left[G^{*}\left(K^{r}\right)\right]$ satisfies either

$$
\left.\frac{d Z\left[G^{*}(K)\right]}{d u}\right|_{k}=0 \text { with } u=u^{\circ}>0
$$

where $u^{0}$ is the value of $u$ such that $\frac{u}{1-u}=\frac{1}{1-\alpha}\left(\frac{\alpha}{1-\gamma^{\theta}}-\frac{\Omega}{\Omega-k}\right)$,

or

$$
\left.\frac{d Z\left[G^{*}(K)\right]}{d u}\right|_{k} \leq 0 \quad \text { with } \quad u=0 .
$$

Conditions (20.1) and (20.2) imply that, given $k$, if $\alpha(1-k / \Omega)>1-\gamma \theta$, then the value of $u$ that maximizes $Z\left[G^{*}(K)\right]$ is $u^{\circ}$, where $0<u^{\circ}<1$. Otherwise, the value of $u$ that maximizes $Z\left[G^{*}(K)\right]$ is zero. This result reflects the fact that the relative sizes of $\alpha(1-k / \Omega)$ and $1-\gamma \theta$ determine the relative sizes of the increase in $K^{\alpha}$, the production of a privileged producer, and the decrease in $p$, the fraction of his production that each producer retains, associated with any increase in $u$ and in $r$.

To simplify the subsequent analysis, while focusing on essential factors, we consider the limiting case as $\alpha$ approaches one. In the limit as $\alpha$ approaches one, we have $\alpha(1-k / \Omega) \gtreqless 1-\gamma \theta$ as $\Omega \gtreqless k / \gamma \theta$.

Considering the limiting case as $\alpha$ approaches one, conditions (19), (20.1), and (20.2), taken together, imply that, with either the privileged tolerating predation by the unprivileged or a fully egalitarian distribution, if $\Omega$ is not larger than $k_{0} / \gamma \theta$, then the unique feasible and Pareto efficient distribution of human capital has $u=0$. This result obtains primarily because, if $\Omega$ is small relative to $k_{0}$, then the minimum fraction of the economy's human capital that the unprivileged would waste by being predators rather than producers would be large.

Alternatively, if $\Omega$ is larger than $k_{0} / \gamma \theta$, then the unique feasible and Pareto efficient distribution of human capital has $k=k_{0}$ and $u=u^{\mathrm{o}}>0$. This result obtains primarily because, if $\Omega$ is large relative to $k_{0}$, then the minimum fraction of the economy's human capital that the unprivileged would waste by being predators rather than producers would 
be small. In addition, given $k=k_{0}$, setting $u$ equal to $u^{\circ}$ reflects the appropriate trade off between the effect of more predators in increasing the amount of human capital wasted by predators and the effect of fewer producers in decreasing the total amount of time and effort devoted to guarding against predation by the privileged. [Recall that $K^{\alpha} G^{*}(K)$, which, from equation (5), equals $\theta /(1-\gamma \theta)$, is the amount of time and effort that each privileged producer must devote to guarding against predation to deter privileged people from being predators and to support a nontrivial equilibrium with positive production.]

What amounts of net consumption by the privileged and the unprivileged are associated with these conditionally Pareto efficient distributions? Given the specification of $u^{\circ}$, equation (8), together with equation (12), implies that

$$
Z\left[G^{*}(K)\right]=(1-\gamma \theta) \Omega^{\alpha} \quad \text { if } u=0
$$

and that

$$
Z\left[G^{*}(K)\right]=v=\alpha^{\alpha}\left(1-\frac{k_{0}}{\Omega}\right)\left[\frac{(1-\alpha)(1-\gamma \theta)}{\gamma \theta-k_{0} / \Omega}\right]^{1-\alpha} \Omega^{\alpha} \text { if } k=k_{0} \text { and } u=u^{\circ}
$$

In the limit as $\alpha$ approaches one, $Z\left[G^{*}(K)\right]$ as given by equation (22) approaches $\Omega-k_{0}$.

\subsection{Unconditional Pareto Efficiency}

We can now derive the set of distributions of human capital that are feasible and unconditionally Pareto efficient. In this derivation we consider three possible situations: Either the distribution of human capital is fully egalitarian, or the distribution of human capital is not fully egalitarian and the privileged deter predation by the unprivileged, or the distribution of human capital is not fully egalitarian and the privileged tolerate predation by the unprivileged. This derivation allows for the possibility that a redistribution of human capital that results in a switch from one of these situations to another could result in a Pareto improvement. Again, considering the limiting case as $\alpha$ approaches one, the partition of feasible distributions of human capital into a set of Pareto efficient distributions and a set

of Pareto inefficient distributions depends only on the relation between $\Omega$ and $\dot{k_{0}} / \gamma \theta$. 
If $\Omega$ is not larger than $k_{0} / \gamma \theta$, then the fully egalitarian distribution of human capital, with either $u=0$ or, equivalently, $K / k=1$, is feasible and Pareto efficient. In addition, as we have seen, if and only if the fully egalitarian distribution is Pareto efficient, then all distributions such that $k \geq k_{0}$ and $1<K / k<(K / k)^{\circ}$ are also feasible and Pareto efficient. Thus, if $\Omega$ is sufficiently small relative to $k_{0}$, then Pareto efficiency implies either deterrence or the fully egalitarian distribution.

Under what conditions would it be Pareto efficient for the privileged to tolerate predation by the unprivileged? Also, under what conditions would the fully egalitarian distribution not be Pareto efficient? If $Z\left[G^{*}(K)\right]$ as given by equation (22) is as large as the supremum of $Z\left[G^{*}(k)\right]$ as given by equation (18), then the distribution of human capital that has $k=k_{0}$ and $u=u^{0}$ is feasible and uniquely Pareto efficient. Given the specification of $(K / k)^{\circ}$, equation (18), together with equation (12), implies that the supremum of $Z\left[G^{*}(k)\right]$ is an increasing function of $u$. In the limit as $u$ approaches one, we have

$$
\lim _{u \rightarrow 1} \sup \left\{Z\left[G^{*}(k)\right]\right\}=\frac{1-\gamma \theta}{\gamma \theta} \Omega^{\alpha}
$$

Considering the limiting case as $\alpha$ approaches one, equations (22) and (23) imply that

$$
Z\left[G^{*}(K)\right] \geq \lim _{u \rightarrow 1} \sup \left\{Z\left[G^{*}(k)\right]\right\} \text { if and only if } \Omega \geq \frac{k_{0}}{2-1 / \gamma \theta}
$$

Equation (24) implies that, if $\Omega$ is sufficiently large relative to $k_{0}$, then the distribution of human capital such that $k=k_{0}$ and $u=u^{\circ}$ is feasible and uniquely Pareto efficient. As we have noted, with this distribution the privileged tolerate predation by the unprivileged.

What distributions of human capital are feasible and Pareto efficient if $\Omega$ is smaller than $\frac{k_{0}}{2-1 / \gamma \theta}$, but $\Omega$ is larger than $k_{0} / \gamma \theta$ ? If $\Omega$ is larger than $k_{0} / \gamma \theta$, then the distribution of human capital such that $k=k_{0}$ and $u=u^{\circ}$ is still feasible and Pareto efficient. In addition, if $\Omega$ is smaller than $\frac{k_{0}}{2-1 / \gamma \theta}$, then some distributions such that $k \geq k_{0}$ and 
$1<K / k<(K / k)^{\circ}$ are feasible and Pareto efficient. This subset of feasible and Pareto efficient distributions includes all distributions such that $k \geq k_{0}, 1<K / k<(K / k)^{\circ}$, and $Z\left[G^{*}(k)\right]$, as calculated from equations (9) and (12), is as large as $Z\left[G^{*}(K)\right]$, as given by equation (22).

In sum, considering the limiting case as $\alpha$ approaches one, if $\Omega$ is not larger than $k_{0} / \gamma \theta$, then the fully egalitarian distribution and all distributions of human capital such that $k \geq k_{0}$ and $1<K / k<(K / k)^{\circ}$ are feasible and Pareto efficient. In this case, because the average endowment of human capital is small relative to the minimum endowment of each unprivileged person, some of the distributions of human capital such that the privileged choose to deter predation by the unprivileged are Pareto efficient. The fully egalitarian distribution is Pareto efficient in this case, but only in this case.

At the other extreme, if $\Omega$ is not smaller than $\frac{k_{0}}{2-1 / \gamma \theta}$, then the distribution of human capital that has $k=k_{0}$ and $u=u^{\circ}$ is feasible and uniquely Pareto efficient. In this case, because the average endowment of human capital is large relative to the minimum endowment of each unprivileged person, Pareto efficiency implies a distribution of human capital such that the privileged choose to tolerate predation by the unprivileged.

In the intermediate case, if $\Omega$ is smaller than $\frac{k_{0}}{2-1 / \gamma \theta}$, but $\Omega$ is larger than $k_{0} / \gamma \theta$, then the distribution of human capital that has $k=k_{0}$ and $u=u^{\circ}$ and all distributions such that $k \geq k_{0}, \quad 1<K / k<(K / k)^{\circ}$, and $Z\left[G^{*}(k)\right]>Z\left[G^{*}(K)\right]$ are feasible and Pareto efficient. In this case, Pareto efficiency allows both a distribution of human capital such that the privileged choose to tolerate predation by the unprivileged as well as some of the distributions of human capital such that the privileged choose to deter predation by the unprivileged.

\section{Rawlsian Distributions of Human Capital}

Now that we have found the set of Pareto efficient distributions of human capital, let us consider which of the distributions in this set is preferred according to the Rawlsian 
criterion. The Rawlsian criterion selects from among the set of Pareto efficient outcomes the outcome that implies the maximum utility for the least advantaged person.

In the present model, net consumption is a cardinal index of utility. Moreover, the net consumption of each unprivileged person is never larger than the net consumption of each privileged person. Accordingly, to apply the Rawlsian criterion in the present model we have to determine which of the Pareto efficient distributions of human capital implies the maximum net consumption for each unprivileged person.

If we were to ignore the possibility of predation, then each person's net consumption would equal that person's production. Moreover, because this model assumes that individual productive activities are independent, and the model also abstracts from trade, the fully egalitarian distribution of human capital would maximize the production of each unprivileged person. Thus, abstracting from predation, the Rawlsian criterion would select the fully egalitarian distribution. In this case, every person would have net consumption equal to $\Omega^{\alpha}$.

The possibility of predation can radically alter this conclusion. Considering the limiting case as $\alpha$ approaches one, we see from conditions (17), (18), (21), and (22) that, if $\Omega$ is not larger than $k_{0} / \gamma \theta$, then the Rawlsian criterion would still select the fully egalitarian distribution of human capital. In this case, every person would have net consumption equal to $(1-\gamma \theta) \Omega$. But, if $\Omega$ is larger than $k_{0} / \gamma \theta$, then the Rawlsian criterion would select the distribution of human capital such that $k=k_{0}$ and $u=u^{\circ}$. In this case, every person would have net consumption equal to $\Omega-k_{0}$.

This result says that, if the average endowment of human capital is large relative to minimum endowment of each unprivileged person, then the distribution that has a positive number of unprivileged people, each of whom has the minimum endowment of human capital, maximizes the net consumption of each unprivileged person. With this unegalitarian distribution of human capital, the privileged producers tolerate predation by the unprivileged, and predation results in maximum consumption for everyone. 


\section{Summary}

This paper has studied the relation between inequality and welfare in a generalequilibrium model in which people can choose to be either producers or predators. We considered a society in which some people (the privileged) are well endowed with human capital, but in which other people (the unprivileged) are poorly endowed with human capital. In this society the interpersonal distribution of human capital has two dimensions: the number of people who are unprivileged and the endowment of human capital of a privileged person relative to the endowment of an unprivileged person. Given the aggregate endowment of human capital, it seemed natural to define a distribution of human capital to be more egalitarian if either the number of people who are unprivileged is smaller or if the ratio of the human capital of a privileged person to the human capital of an unprivileged person is smaller.

We first analysed how the choice of the privileged between either deterring or tolerating predation by the unprivileged depends on the interpersonal distribution of human capital. We found that, if the number of people who are unprivileged is large, but a privileged person does not have too much human capital relative to an unprivileged person, then the privileged allocate enough time and effort to guarding against predation to deter the unprivileged from being predators. Otherwise, the privileged tolerate predation by the unprivileged. These results obtain because the larger the number of unprivileged people the larger would be the loss to producers from tolerating predation and because the smaller the ratio of the human capital of a privileged person to the human capital of an unprivileged person the less is the time and effort allocated to guarding against predation that is necessary to deter the unprivileged from being predators.

We also found that, if the distribution of human capital is such that the privileged choose to tolerate predation by the unprivileged, then a decrease in the number of people who are unprivileged would result fewer people choosing to be predators. But, interestingly, if the distribution of human capital is such that the privileged choose to deter predation, 
then a sufficient decrease in the number of people who are unprivileged would cause the privileged to choose instead to tolerate predation by the unprivileged. The explanation for this apparently paradoxical possibility that a more egalitarian distribution of human capital can result in predation being tolerated rather than deterred was that a decrease in the number of unprivileged people reduces the loss to producers from tolerating predation.

Next, we analysed the welfare properties of the interpersonal distribution of human capital. We partitioned the feasible distributions of human capital into a set of Pareto efficient distributions and a set of Pareto inefficient distributions. The key to understanding Pareto efficiency in this model was to observe that the possibility of predation can affect aggregate net consumption in two distinct ways. First, any time and effort devoted to guarding against predation reduces the net consumption of producers. Second, if the producers tolerate predation by the unprivileged, then the human capital of the unprivileged is wasted by not being used productively.

We found that the partition between Pareto efficient distributions and Pareto inefficient distributions depends on the economy's average endowment of human capital relative to the minimum endowment that each unprivileged person has by virtue of birth. Specifically, if the average endowment of human capital is small relative to the minimum endowment of each unprivileged person, then some of the distributions of human capital such that the privileged choose to deter predation by the unprivileged are Pareto efficient. The fully egalitarian distribution is also Pareto efficient in this case, but only in this case.

But, if the average endowment of human capital is large relative to the minimum endowment of each unprivileged person, then Pareto efficiency implies a distribution of human capital with a positive number of unprivileged people and with each unprivileged person having the minimum endowment of human capital. With such an unegalitarian distribution, the privileged choose to tolerate predation by the unprivileged.

Taken together, because the minimum endowment of human capital presumably varies little across economies, these results suggest that in economies in which the average person 
has little human capital some of the distributions of human capital such that the privileged choose to deter predation by the unprivileged and the fully egalitarian distribution are Pareto efficient, whereas in economies in which the average person has a large anount of human capital only an unegalitarian distribution such that the privileged choose to tolerate predation by the unprivileged would be Pareto efficient. Lhterestingly, in economies in which the average person has a large amount of human capital the fully egalitarian distribution would not be Pareto efficient.

Then, we applied the Rawlsian criterion, and we deternined which of the Pareto efficient distributions of human capital maximizes the net consumption of the unprivileged. Because this model assumes that individual productive activities are independent, and the model also abstracts from trade, without the possibility of predation the Rawlsian criterion would select the fully egalitarian distribution. But, the possibility of predation can radically alter this result. We found that with the possibility of predation, if the average endowment of human capital is large relative to the minimum endowment of each unprivileged person, as presumably would be the case in economies in which the average person has a large amount of human capital, then the Rawlsian criterion would select the Pareto efficient distribution of human capital with a positive number of unprivileged people and with each unprivileged person having the minimum endowment of human capital. With this unegalitarian distribution of human capital, the privileged producers tolerate predation by the unprivileged, and predation results in maximum consumption for everyone. 


\section{References}

Grossman, Herschel I. "Production, Appropriation, and Land Reform," Anerican Econonic Review, 84, June 1994, 705-712.

Grossman, Herschel I. "Robin Hood and the Redistribution of Property Income," European Journal of Political Economy, 11, September 1995, 399-410.

Grossman, Herschel I. and Kim, Minseong. "Swords or Plowshares? A Theory of the Security of Claims to Property," Journal of Political Economy, 10.3, December 1995, 1275-1288.

Grossman, Herschel I. and Kim, Minseong. "Predation and Production," in Michelle R. Garfinkel and Stergios Skaperdas, eds., The Political Economy of Confict and Appropriation, New York: Cambridge University Press, 1996a..

Grossman, Herschel I. and Kim, Minseong. "Morality and Predation," unpublished, May 1996b.

Moselle, Boaz and Polak, Ben. "Anarchy, Organized Crime and Extortion: A Cynical Theory of the State," unpublished, 1995.

Rawls, John. A Theory of Justice, Cambridge: Harvard University Press, 1971.

Skaperdas, Stergios and Syropoulos, Constantinos. "Competitive Trade with Conflict," in Michelle R. Garfinkel and Stergios Skaperdas, eds., The Political Economy of Conflict and Appropriation. New York: Cambridge University Press, 1996.

Usher, Dan. "Theft as a Paradigm for Departures from Efficiency, " Oxford Economic Papers, 39, June 1987, 235-252; reprinted as Chapter III in Dan Usher, The Welfare Economics of Markets, Voting and Predation, Ann Arbor: The University of Michigan Press, 1992.

Wong, Yue-Chim Richard. "An Economic Analysis of the Crime Rate in England and Wales, 1857-92," Economica, 62, May 1995, 235-246. 